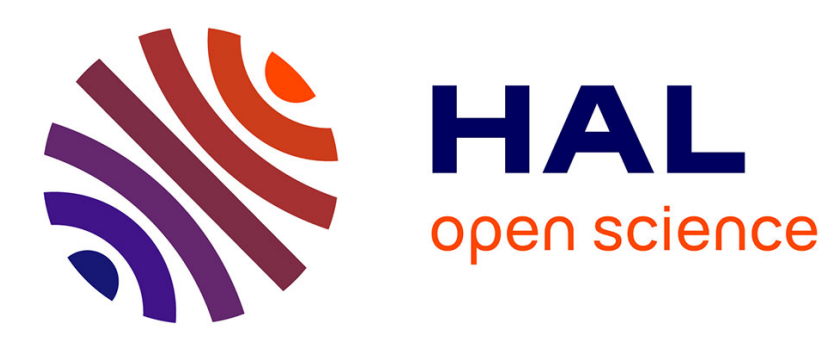

\title{
Computations of a shock layer flow field with global and detailed chemistry models
}

\author{
Marie-Claude Druguet, Arnaud Bultel, Julien Annaloro, Pierre Omaly
}

\section{To cite this version:}

Marie-Claude Druguet, Arnaud Bultel, Julien Annaloro, Pierre Omaly. Computations of a shock layer flow field with global and detailed chemistry models. 30th International Symposium on Shock Waves 1, 2017, 978-3-319-46211-0. hal-03575458

\section{HAL Id: hal-03575458 \\ https://hal.science/hal-03575458}

Submitted on 15 Feb 2022

HAL is a multi-disciplinary open access archive for the deposit and dissemination of scientific research documents, whether they are published or not. The documents may come from teaching and research institutions in France or abroad, or from public or private research centers.
L'archive ouverte pluridisciplinaire HAL, est destinée au dépôt et à la diffusion de documents scientifiques de niveau recherche, publiés ou non, émanant des établissements d'enseignement et de recherche français ou étrangers, des laboratoires publics ou privés. 


\title{
Computations of a shock layer flow field with global and detailed chemistry models
}

\author{
Marie-Claude Druguet \\ Aix-Marseille Université - CNRS UMR 7343 - Laboratoire IUSTI \\ 5 rue Enrico Fermi, 13013 Marseille, France \\ Corresponding author: Marie-Claude.Druguet@univ-amu.fr \\ Arnaud Bultel \\ Normandie Université - CNRS UMR 6614 - Laboratoire CORIA \\ 76800 St Etienne du Rouvray, France \\ Julien Annaloro and Pierre Omaly \\ CNES - DCT/TV/PR, BPI 1717, 18 Avenue Edouard Belin \\ 31401 Toulouse Cedex 9, France
}

\section{Introduction}

The present work is a first step in computing a reactive gas flow behind a shock wave with detailed collision-radiative models. If simulating high-temperature, highenthalpy, non-equilibrium gas flows in shock layers has been widely done so far with global models for the chemical kinetics and the vibrational non-equilibrium, it is quite new to compute such flow fields with detailed chemistry models. This is now possible as the computation and memory resources of the computers allow to run CFD codes with detailed models. State-specific vibrational models are efficient to model both the chemical reactions and the vibrational non-equilibrium at once, without making strong assumptions (like Boltzmann distribution) as it it the case with multi-temperature models for vibrational non-equilibrium modeling.

The continuous, non equilibrium, hypersonic gas flow past a space probe is modeled with axi-symmetric, compressible, time-dependent conservation equations that include the conservation equations of mass of each reacting chemical species, of momentum (Navier-Stokes equations), of total energy, and of non equilibrium vibrational energies. The code used to solve those equations is the Parallel Implicit NonEquilibrium Navier-Stokes (PINENS) code, developed by Druguet [1]. This code is based on a finite volume formulation on structured grids, where the convective fluxes at the interfaces between cells are evaluated with the approximate Riemann solver of Roe. The time resolution is implicit and done by the data parallel line relaxation (DPLR) method [2].

The present study is done on the flow past an axisymmetric blunt body for the following point of a Mars Sampler Return Orbiter (MSRO) trajectory : $\rho=2.93310^{-4}$ $\mathrm{kg} / \mathrm{m}^{3}, \mathrm{~V}=5223 \mathrm{~m} / \mathrm{s}, \mathrm{T}=140 \mathrm{~K}$. This corresponds to a test case (TC3) proposed by the ESA working group on radiation of high-temperature gases in atmospheric entry [3]. Under the conditions of an atmosphere composed of $100 \% \mathrm{CO}_{2}$ and of the 
considered chemical kinetics models [4], the molecules $\mathrm{CO}_{2}$ dissociate through the shock wave leading to a gas mixture composed of 5 species : $\mathrm{CO}_{2}, \mathrm{CO}, \mathrm{O}_{2}, \mathrm{C}, \mathrm{O}$. The molecular species are supposed to be in a vibrational non equilibrium state. The thermodynamical state of the gas mixture is then described by several temperatures, the equilibrium temperature $T$, and one vibrational temperature for each vibrating molecule.

Before modeling the non equilibrium and reactive gas flowing in the shock layer surrounding a probe with detailed models, global models are tested and compared. First, two global chemical kinetics rate models (the usual Park model for Mars entries [4] and a more recently developed model from CORIA) are compared and their effect on the flow field in the front shock layer past an axi-symmetric probe is assessed. Thermal non-equilibrium is modeled with a multi-temperature vibrational relaxation model, where vibration-translation [4] and vibration-vibration exchanges [5] are taken into account and their respective influence on the flow field solution assessed. Finally, preliminary computations with a detailed chemical kinetics model [6] are done in a one-dimension configuration, using the Rankine-Hugoniot equations.

\section{Comparison of global chemical kinetics rates for $\mathrm{CO}_{2}$ gas mixture}

Two chemical kinetics models for gas mixtures resulting from $\mathrm{CO}_{2}$ dissociation through a shock wave are compared. The first model (Table 1) - referred to as kin302 - is the Park model slightly corrected by Bultel for the backward rates, in order to restore the equilibrium constant in reaction rates 11 to 18 . The second model (Table 2) is a new model proposed by Annaloro and Bultel at CORIA (referred to as kin303) [6].

Table 1 TC3 booklet Park chemical kinetics model corrected by Bultel (referred to as kin302 in the figures), for 5 species: $\mathrm{CO}_{2}, \mathrm{O}_{2}, \mathrm{CO}, \mathrm{C}, \mathrm{O}$

\begin{tabular}{lrcrrrrrrr}
\hline Reaction no & $A_{f}$ & $b_{f}$ & $E_{f}(\mathrm{~K})$ & $A_{b}$ & $b_{b}$ & $E_{b}(\mathrm{~K})$ & $A_{e q}$ & $b_{e q}$ & $E_{e q}$ \\
\hline $01-03$ & $6.900 \mathrm{E}+15$ & -1.5 & 63275 & $1.140 \mathrm{E}+05$ & -0.75 & 535 & $6.053 \mathrm{E}+10$ & -0.75 & 62740 \\
$04-05$ & $1.380 \mathrm{E}+16$ & -1.5 & 63275 & $2.280 \mathrm{E}+05$ & -0.75 & 535 & $6.053 \mathrm{E}+10$ & -0.75 & 62740 \\
\hline $06-08$ & $2.000 \mathrm{E}+15$ & -1.5 & 59500 & $2.000 \mathrm{E}+06$ & -1 & 0 & $1.000 \mathrm{E}+09$ & -0.5 & 59500 \\
$09-10$ & $1.000 \mathrm{E}+16$ & -1.5 & 59500 & $1.000 \mathrm{E}+07$ & -1 & 0 & $1.000 \mathrm{E}+09$ & -0.5 & 59500 \\
\hline $11-13$ & $2.300 \mathrm{E}+14$ & -1 & 129000 & $5.134 \mathrm{E}+06$ & -1 & 0 & $4.480 \mathrm{E}+07$ & 0 & 129000 \\
$14-15$ & $3.400 \mathrm{E}+14$ & -1 & 129000 & $7.590 \mathrm{E}+06$ & -1 & 0 & $4.480 \mathrm{E}+07$ & 0 & 129000 \\
\hline 16 & $2.100 \mathrm{E}+07$ & 0 & 27800 & $3.469 \mathrm{E}+06$ & 0.25 & 24560 & $6.054 \mathrm{E}+01$ & -0.25 & 3240 \\
17 & $2.330 \mathrm{E}+03$ & 0.5 & 65710 & $3.148 \mathrm{E}+06$ & -0.25 & -550 & $7.402 \mathrm{E}-04$ & 0.75 & 66260 \\
18 & $3.900 \mathrm{E}+07$ & -0.18 & 69200 & $8.705 \mathrm{E}+08$ & -0.68 & -300 & $4.480 \mathrm{E}-02$ & 0.5 & 69500 \\
\hline
\end{tabular}

A comparison of the flow variables (temperature, pressure, density) obtained successively with the 2 kinetics models is shown in Fig. 1. The observed differences on 
Table 2 Annaloro and Bultel chemical kinetics model [6] (referred to as kin303 in the figures) for 5 species: $\mathrm{CO}_{2}, \mathrm{O}_{2}, \mathrm{CO}, \mathrm{C}, \mathrm{O}$

\begin{tabular}{lrrrrrrrrr}
\hline Reaction no & $A_{f}$ & \multicolumn{1}{c}{$b_{f}$} & $E_{f}(\mathrm{~K})$ & $A_{b}$ & $b_{b}$ & $E_{b}(\mathrm{~K})$ & $A_{e q}$ & $b_{e q}$ & $E_{e q}$ \\
\hline $01-03$ & $5.400 \mathrm{E}+14$ & -1.407 & 64010 & $8.922 \mathrm{E}+03$ & -0.657 & 1270 & $6.053 \mathrm{E}+10$ & -0.75 & 62740 \\
$04-05$ & $1.080 \mathrm{E}+15$ & -1.407 & 64010 & $1.784 \mathrm{E}+04$ & -0.657 & 1270 & $6.053 \mathrm{E}+10$ & -0.75 & 62740 \\
\hline $06-08$ & $3.460 \mathrm{E}+10$ & -0.474 & 58700 & $3.460 \mathrm{E}+01$ & 0.026 & -800 & $1.000 \mathrm{E}+09$ & -0.5 & 59500 \\
$09-10$ & $1.730 \mathrm{E}+11$ & -0.474 & 58700 & $1.730 \mathrm{E}+02$ & 0.026 & -800 & $1.000 \mathrm{E}+09$ & -0.5 & 59500 \\
\hline $11-13$ & $2.300 \mathrm{E}+14$ & -1 & 129000 & $5.134 \mathrm{E}+06$ & -1 & 0 & $4.480 \mathrm{E}+07$ & 0 & 129000 \\
$14-15$ & $3.400 \mathrm{E}+14$ & -1 & 129000 & $7.590 \mathrm{E}+06$ & -1 & 0 & $4.480 \mathrm{E}+07$ & 0 & 129000 \\
\hline 16 & $2.185 \mathrm{E}+08$ & -0.25 & 27315 & $3.610 \mathrm{E}+06$ & 0 & 24075 & $6.054 \mathrm{E}+01$ & -0.25 & 3240 \\
17 & $2.300 \mathrm{E}+03$ & 0.5 & 65710 & $3.107 \mathrm{E}+06$ & -0.25 & -550 & $7.402 \mathrm{E}-04$ & 0.75 & 66260 \\
18 & $3.900 \mathrm{E}+07$ & -0.18 & 69200 & $8.705 \mathrm{E}+08$ & -0.68 & -300 & $4.480 \mathrm{E}-02$ & 0.5 & 69500 \\
\hline
\end{tabular}

the shock stand-off distance may be explained by looking at the chemical source terms resulting from the various chemical rates, for example the source term for the $\mathrm{CO}_{2}$ density (Fig. 2). The chemical source term corresponding to the dissociation of $\mathrm{CO}_{2}$ is smaller (in absolute value) in CORIA model than in Park model. Because less dissociation of $\mathrm{CO}_{2}$ occur, less thermal energy is taken away from the high-temperature gas in the shock layer. This makes the shock stand further from the probe surface.
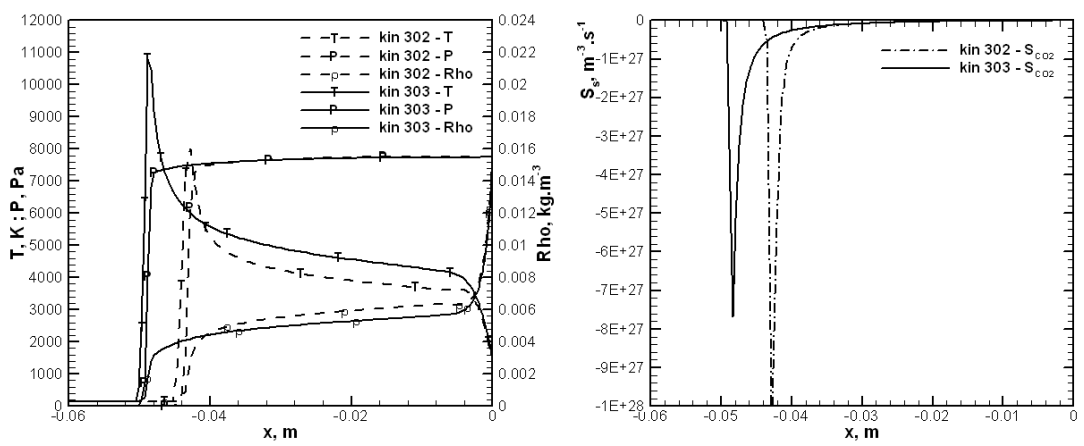

Fig. 1 Temperature, pressure, density profiles Fig. 2 Chemical source term for $\mathrm{CO}_{2}$ densities along the stagnation line. Comparison between along the stagnation line. Comparison between the two chemical rates models. the two chemical rates models.

\section{Multi-temperature model for vibrational relaxation}

When modeling vibrational relaxation, the following vibrational energy conservation equation is added to the set of equations already gathering the Navier-Stokes, 
mass and total energy conservation equations :

$$
\frac{\partial E_{V_{v}}}{\partial t}+\operatorname{div}\left(E_{V_{v}} \vec{V}\right)=\omega_{C_{v}} \frac{E_{V_{v}}}{\rho_{v}}+\omega_{V_{v}}^{V T}+\omega_{V_{v}}^{V V}, \quad v=\text { vibrating species }
$$

The first term in the right hand side of eq.(1), $\omega_{C_{v}} E_{V_{v}} / \rho_{v}$, comes from a variable change in writing the vibrational energy conservation equation. The second and third term are the vibrational source terms for the Vibration-Translation (VT) and the Vibration-Vibration (VV) exchanges.

The vibrational energy conservation equation source term corresponding to the VT exchanges is written as [4] :

$$
\omega_{V_{v}}^{V T}=\frac{E_{V_{v}}(T)-E_{V_{v}}\left(T_{V_{v}}\right)}{\tau_{v}^{V T}}
$$

where $\tau_{v}^{V T}$ is the characteristic time of relaxation for VT exchanges (see Refs. [4] or [3]).

According to Stupochenko et al. [5], the source term for the vibrational energy conservation equation due to the $\mathrm{VV}$ exchanges between two molecular species, $v$ and $w$, may be expressed as :

$$
\omega_{V_{v w}}^{V V}=\frac{1}{p \tau_{v w}^{V V}} \frac{T}{\theta_{V_{w}}}\left\{E_{V_{w}}\left(E_{V_{v}}+\rho_{v} R_{v} \theta_{V_{v}}\right) \exp \frac{\theta_{V_{w}}-\theta_{V_{v}}}{T}-E_{V_{v}}\left(E_{V_{w}}+\rho_{w} R_{w} \theta_{V_{w}}\right)\right\},
$$

where $p \tau_{v w}^{V V}$ is the characteristic time of vibrational relaxation through $\mathrm{VV}$ exchanges. The source term $\omega_{V_{v w}}^{V V}$ corresponds to the vibrational energy gained by the molecule $v$ when exchanging vibrational energy with the molecule $w$ during collisions taking place in a mixture composed of two chemical species only. When the vibration-vibration exchanges take place in a gas mixture composed of more than two species, a more general expression for the VV energy source term must be used : $\omega_{V_{v}}^{V V}=\sum_{w=1}^{n_{v}} X_{w} \omega_{V_{v w}}^{V V}$, where $X_{w}$ is the mole fraction of molecule $w$ in the gas mixture.

Using the Park expressions for $\tau^{V T}$, the evolution of the vibrational and translationalrotational temperatures along the stagnation line is presented in Fig. 3. The vibrational temperature of the second mode of vibration of $\mathrm{CO}_{2}$ is close to the translational temperature, meaning that the second mode is easily excited and reaches equilibrium fast. This is due to the fact that $p \tau_{\mathrm{CO}_{2}(2), s}^{V T}$ is lower than other $p \tau_{v, s}^{V T}$. On the other hand, the third mode of vibration of $\mathrm{CO}_{2}$ is excited with some delay. Indeed, its characteristic relaxation time of vibration is the largest one among the three modes of vibration of $\mathrm{CO}_{2}$. It is a mode that is known to be not easily excited. The relaxation time of $\mathrm{O}_{2}$ is globally larger than that of $\mathrm{CO}_{2}(3)$, which makes the vibrational relaxation of $\mathrm{O}_{2}$ slower. As for the vibrational temperature of $\mathrm{CO}$, it is the further one from the translation temperature behind the shock, which means that the molecule $\mathrm{CO}$ is in a strong vibrational non-equilibrium state. This is due to the characteristic relaxation time of this molecule that is larger than the other characteristic relaxation times. 

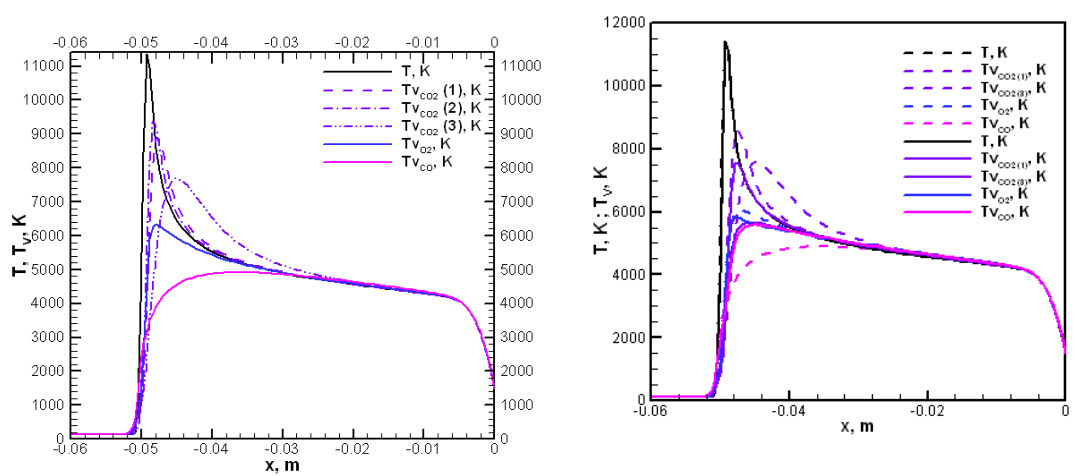

Fig. 4 Translational and vibrational tempera-

Fig. 3 Translational and vibrational tempera- tures along the stagnation line, obtained with tures along the stagnation line, obtained with a a multi-temperature vibration relaxation model. multi-temperature vibration relaxation model.

Effect of the VV exchanges on the vibration relaxation in the shock layer.

\section{Chemical and vibrational non equilibrium modeling with detailed models}

The reactions between chemical species on their vibrational excited states and the spatial evolution of these pseudo-species (chemical species on various vibrational states) behind a normal shock wave resolved with a one-dimension RankineHugoniot solver, were simulated by CORIA, by means of one of the detailed collisional-radiative models recently developed, $\mathrm{CoRaN}_{2} \mathrm{~N}$ [6]. This numerical experiment is done for the typical Fire II flight experiment (near the peak heating undergone by the thermal protection) which corresponds to the following upstream conditions : $\mathrm{M}_{0}=32, \mathrm{p}_{0}=54 \mathrm{~Pa}$, and $\mathrm{T}_{A_{0}}=274 \mathrm{~K}$. Results obtained at CORIA with one-dimension Rankine-Hugoniot simulations are the space evolution of $\mathrm{N}_{2}$ and $\mathrm{N}$ concentrations behind the shock wave, for the 69 vibrational states of $\mathrm{N}_{2}$ and the fundamental electronic state of $\mathrm{N}$ (see Figs. 5 and 6). This model will be implemented in the CFD code PINENS developed at IUSTI, in which the shock resolution is done with a shock capturing method. The expected results to be presented at the symposium are the evolution of the chemical species on their vibrational excited states in a two-dimension shock layer flow resolved by the PINENS code. Comparisons between results obtained with detailed models and results obtained with global models will also be presented, to show how the global models perform compared to the detailed models in the prediction of the chemical species and vibrational states evolution past a shock wave. 

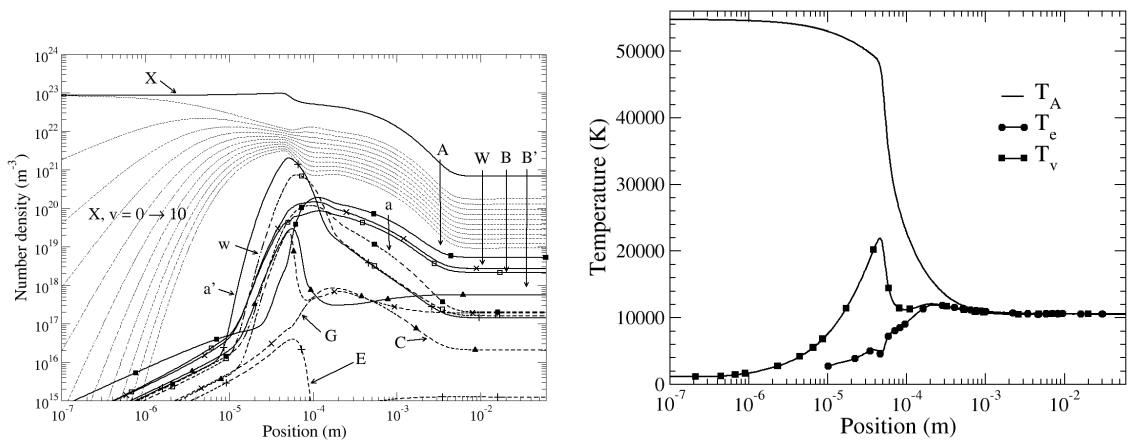

Fig. 5 Post-shock spatial evolution of the first Fig. 6 Post-shock spatial evolution of the 11 vibrational states of $\mathrm{N}_{2}(X)$, the electronic heavy-particle temperature $\mathrm{T}_{A}$, the electron temground state, and the excited states of $\mathrm{N}_{2}$. perature $\mathrm{T}_{e}$, and the vibrational temperature $\mathrm{T}_{V}$ of the electronic ground state of $\mathrm{N}_{2}$.

\section{Summary and concluding remarks}

The non equilibrium and reactive flow field in the shock layer past an axi-symmetric blunt body entering a Mars-type atmosphere was modeled and simulated with the CFD code PINENS. Two global chemical kinetics rate models were compared. The results showed that the shock standoff distance predicted by the two models differ greatly, meaning that the chemical reactions influence the flow field a lot. A multi-temperature model for $\mathrm{CO}_{2}, \mathrm{O}_{2}, \mathrm{CO}$ vibrationally relaxing in a gas mixture composed of the same molecules plus atoms $\mathrm{C}$ and $\mathrm{O}$, was implemented in PINENS code. The results showed that the vibration of the molecules in the shock layer relaxes towards a non-equilibrium state. Results obtained with the Park characteristic times for vibrational relaxation, showed that the symmetric stretching mode, and particularly the bending mode of $\mathrm{CO}_{2}$, are close to equilibrium with the translational mode, even when the VV exchanges are not taken into account. The anti-symmetric mode relaxes much slower than the other two modes. This study also showed that VV exchanges are important in the shock layer flow, for that particular atmosphere entry condition. When the VV exchanges are taken into account, the vibrational temperatures converge towards the same value much faster, making the equilibrium of vibration with translation much faster.

In parallel to the computations done with PINENS code and global models, calculations with a one-dimensional Rankine-Hugoniot code and detailed collisionalradiative models were conducted behind a normal shock wave. The results showed that the Boltzmann distribution is not observed in the flow area behind the shock wave.

Perspectives to this work are to implement vibrationally specific models into the CFD code PINENS, in order to predict more precisely the non-equilibrium behavior of the gas mixture behind a shock wave. The comparison of state-specific vibrational 
results with multi-temperature results will show how the global models perform compared to the detailed models.

\section{Acknowledgements}

This work was granted access to the High-Performance Computing resources of the "Institut du Développement et des Ressources Informatiques et Scientifiques" (IDRIS) under the allocation i20142b9076 made by GENCI (Grand Equipement National du Calcul Scientifique).

\section{References}

1. Druguet M.-C., Candler G.V., Nompelis I. (2005) Effects of Numerics on Navier-Stokes Computations of Hypersonic Double-Cone Flows, AIAA Journal, 43(3), pp. 616-623.

2. Wright M.J., Bose D., Candler G.V. (1998) Data-Parallel Line Relaxation Method for the Navier-Stokes Equations, AIAA Journal, 36(9), pp. 1603-1609.

3. Proceedings of the International Workshop on Radiation of High-Temperature Gases in Atmospheric Entry, ESA SP-583 (2004), ESA SP-629 (2006), ESA SP-667 (2008), ESA SP-689 (2010).

4. Park C., Howe J., Jaffe R., Candler G.V. (1994) Review of chemical-kinetics problems of future NASA missions, 2: Mars entries, Journal of Thermophysics and Heat Transfer, 8(1), pp. 9-23.

5. Stupochenko Y.V., Losev S.A., Osipov A.I., (1967) Relaxation in Shock Waves. SpringerVerlag, New-York.

6. J. Annaloro, A. Bultel. P. Omaly (2014) Collisional-Radiative Modeling Behind Shock Waves in Nitrogen, Journal of Thermophysics and Heat Transfer, DOI: 10.2514/1.T4263. 